\title{
edmetic
}

Revista de Educación Mediática y TIC

Presentación: Universidad y red, el flujo desde lberoamérica

La mayor innovación que la universidad pueda esperar del mundo digital dependerá de una buena y ambiciosa idea educativa. Esta puede ser la idea más general que se puede obtener de los cinco trabajos que constituyen este monográfico dedicado a la "Universidad red desde Iberoamérica", volumen 5, número 2, 2016 de la Revista EDMETIC que tengo el placer de presentar.

El debate educativo, tenso a veces, entre la tecnofobia y la tecnofilia se viene abriendo paso a posturas más críticas que, en vez de posicionarse entre el bien y el mal, apuestan por evaluar el impacto educativo de lo digital desde distintas disciplinas, desde múltiples contextos y desde diversas necesidades educativas. Todo invita a pensar que si bien es cierto se puede hablar de una emergente cultura del aprendizaje global, aupadas por infraestructuras como Internet, las visiones educativas sobre la docencia, la investigación y la proyección social de la universidad con tecnología son formas propias de entender el carácter global de una forma de la interacción social donde se aloja una parte de nuestro quehacer en la actualidad, la red.

La identificación de tecnologías (por ejemplo, la impresión 3D o Internet de las cosas) y la regeneración de conceptos y procesos en la universidad en virtud de lo digital (por ejemplo, los MOOC O la ciencia 2.0), aunque importantes, son en realidad la punta del iceberg de una serie de cambios culturales de mayor calado que implican la sintonía de muchas variables. Estos cinco trabajos examinan algunas de estas variables. 
Cada propuesta aquí implica una respuesta educativa enriquecida en Internet. No obstante, ya que el ámbito de Iberoamérica supone reconocer un escenario social dotado de diversidad, complejidad y creatividad particulares, todos los trabajos buscan atender la pregunta que motivó este monográfico: ¿cómo las universidades iberoamericanas vienen empleando Internet con la finalidad de atender sus necesidades educativas concretas? La diferencia no está en la noción de la red, sino en las necesidades y nociones educativas de las que dependen los proyectos en este monográfico.

Temáticamente, en este monográfico se cubren tópicos como: gestión digital, escenarios educativos, educomunicación, creencias docentes y estrategias docentes. Como es natural, presentaré cada trabajo, pero también y en vez de abultar en la descripción del mismo -disponible en el propio trabajo- opto por sugerir una interrogante derivada de su lectura. Esto último con la finalidad de aportar algo más en la perspectiva del trabajo en vez de reproducir sus partes.

Teresa Guzmán Flores y Alexandro Escudero Nahón encaran a través de "Implementación del Sistema Multimodal de Educación de la Universidad Autónoma de Querétaro, México", el reto organizacional de pensar la universidad en ambientes tecnológicamente enriquecidos. Concretamente se ocupan de evaluar el contraste entre el diseño y la aplicación de los sistemas multimodales en la universidad. Sus resultados apuntan a no descuidar dos desafíos evidentes en la praxis: un cierto estrés procedimental en la adopción de materiales digitales y la necesidad de atender variables discretas en el proceso de transversalización horizontal del modelo. Con todo, ¿̇está la universidad Iberoamericana preparada para un cambio cultural o solo adapta tecnología?

Por su parte, Concepción de María Mendieta Baltodano en su trabajo "Integración en el contexto de la educación superior pública de Nicaragua: El nuevo modelo educativo de la UNAN-Managua" busca poner de manifiesto la importancia de la formación en competencias para el ámbito tecnológico que promueva un cambio didáctico. Al evaluar el papel de los nuevos entornos de aprendizaje en red dentro del nuevo modelo educativo universitario, detecta tres líneas de acción necesarias para consolidar el cambio educativo con tecnología: la formación docente continua, la gestión 


\section{Presentación: Universidad red, el flujo desde Iberoamérica}

universitaria y la promoción docente del uso de tecnología en el aula. Frente a ello, se puede pensar en definir żqué perfil y dimensiones de la Competencia Digital Docente tiene -y debe tener- el profesor universitario en Iberoamérica? João Canavilhas, Adoración Merino-Arribas y Maicon Elias Kroth en "Impacto socioeducativo del periódico escolar: metaanálisis de tres proyectos de educomunicación en Brasil, España y Portugal" hacen de la educomunicación su objeto de estudio. Toman en cuenta tres proyectos de educación para los medios en escuelas tuteladas por universidades de Brasil, Portugal y España para identificar cómo educación para los medios de comunicación permiten formar ciudadanos más críticos. Basándose en el metaanálisis identifican que la participación social en red es una constante en proyectos que buscan sensibilizar a los jóvenes a ser más activos en su comunidad. En este caso, ¿cómo extrapolar o reutilizar criterios y dinámicas de trabajo de movimientos sociales en red para usarlos en el aula?

Blanca Isela Robles Haros, María Teresa Fernández Nistal y Javier José Vales García en "Creencias de profesores universitarios sobre la enseñanzaaprendizaje de cursos B-Learning. Revisión bibliográfica" encaran el poco frecuente mundo de las actitudes docentes frente a la tecnología en la investigación educativa. Para ello realizan una revisión bibliográfica sobre los estudios de las creencias de los profesores sobre cómo enseñar y cómo aprender en la modalidad Blended Learning (B-learning). Además de constatar que existe una notoria escasez de trabajos sobre el tema, las actitudes docentes detectadas se ubicarían en una etapa de transición entre las posturas tradicionales y las derivadas de una visión constructivista. ¿̇Ha superado Latinoamérica su visón de "buena educación" centrada en la presencialidad?

Y, finalmente, Óscar Julián Montoya Álvarez, Marcela Georgina Gómez Zermeño y Nancy Janett García Vázquez en "Estrategias para mejorar la comprensión lectora a través de las TIC" se esmeran en explorar los niveles de eficacia de la modalidad B-learning sobre el mejoramiento de los niveles de compresión lectora en una institución colombiana. Para ello compararon resultados de pre-lectura, lectura y post-lectura y los resultados mostraron el impacto positivo en el grupo experimental quienes utilizaron el recurso 
pedagógico digital. No obstante, ¿̇cabe repensar los parámetros de comprensión lectura para explicar los procesos de lectura digital?

Animo a los lectores de este monográfico a formular otras preguntas y, con ello, arribar a nuevas formas de comprensión e investigación.

Dr. Cristóbal Suárez Guerrero Universidad de Valencia cristobal.suarez@uv.es 